\title{
Comparative Studies on Different Sire Evaluation Methods: Review
}

\author{
Vikram Jakhar*, A.S. Yadav and S.S. Dhaka \\ Department of animal genetics and breeding, LUVAS, Hisar, Haryana, India \\ *Corresponding author
}

\begin{tabular}{|l|}
\hline Ke y w o r d s \\
Sire evaluation, \\
Breeding value, \\
LSM, BLUP, \\
DFREML, OLS. \\
\hline Article Info \\
\hline $\begin{array}{l}\text { Accepted: } \\
\text { 30 October } 2017 \\
\text { Available Online: } \\
\text { 10 November } 2017\end{array}$ \\
\hline
\end{tabular}

A B S T R A C T

The major thrust in dairy cattle breeding programme has been to identify potential parents with high breeding value for next generation. In general, two breeding strategies are available for improvement of cattle, i.e. selective breeding with in a breed and cross breeding among breeds (Falconer and Mackay, 1996). For the formulation of effective genetic improvement programme, basic knowledge of genetic parameters of a herd must be known with maximum accuracy. To improve the efficiency and accuracy of sire evaluation programmes many sire indices has been developed by using the procedures of Simple Daughter Average (SDA), Ordinary Least-squares (OLS), Regressed LeastSquares (RLS), Best Linear Unbiased Prediction (BLUP) and Derivative free restricted maximum likelihood (DFREML).The comparison of efficiency of these sire evaluation methods was done by using the different criteria like coefficient of determination, coefficient of variation, rank correlations and error variance. The literature is dotted with conflicting reports (Pundir et al., 2004; Dhaka et al., 2004; Banik and Gandhi, 2006; Raja, 2010) on comparative evaluation of various sire evaluation techniques. The BLUP method was found to be more efficient, accurate in the some studies. While in some studies the derivative free restricted maximum likelihood method was superior over other methods. This review summarizes findings of various researches relating to comparative efficiency of sire evaluation methods for estimation of breeding values for efficient selection in animal breeding.

\section{Introduction}

The aim of animal breeder is to select the genetically superior bulls to bring out genetic improvement in the productive as well as reproductive performance of the herd. Suitable criterion of selection which gives best discrimination among sires should be formulated to evaluate sires on the basis of performance of their daughters considering both productive as well as reproductive traits. Sire evaluation is one of the most important in animal breeding and selection. The effectiveness of sire evaluation is the backbone of any breed improvement programme as the contribution of sire path is higher than the dam path for the overall genetic improvement for a trait. The introduction of artificial insemination has made it all the more important to disseminate the superior germplasm for widespread use among farms and community of this continent. Therefore the main aim of sire evaluation is to obtain an accurate, efficient and ranking them according to their merit so as to enable the breeder to choose the best bulls. An early and accurate appraisal is essential for maximum genetic gain for 
computation of breeding value of sire. There are different methods of sire evaluation viz., least squares (LSM), regressed least squares (RLS), simple daughter average (SDA), ordinary least square(OLS), best linear unbiased prediction (BLUP) and derivative free restricted maximum likelihood (DFREML) for single as well as multiple traits models. The effectiveness of different sire evaluation methods was compared by using error variance, coefficient of determination (\%), coefficient of variation (\%) and rank correlations. The most efficient method had the lowest error variance. Higher the coefficients of determination (R2-Value) from fitting a model, higher the accuracy. The method, maintaining the coefficient of variation $(\mathrm{CV} \%)$ of the population near to the $\mathrm{CV}$ (\%) unadjusted data was the most efficient method. Higher (near to unity) rank correlation amongst the sires from different sire evaluation methods revealed higher degree of similarity of ranking from different methods. In dairy cattle sire evaluation based different traits like milk yield, age at first calving (AFC), first calving interval (FCI), first lactation milk yield (FLMY), first lactation period (FLP), weight at first calving (WFC) and first service period (FSP) were conducted in various studies.

\section{Comparison of different sire evaluation methods}

Lush (1933) was the first who discussed different sire indices and recommended equal parent index to be the best as it was simple for field use. Gandhi and Gurnani (1991) compared the breeding value of Sahiwal sires using BLUP and least squares methods on the basis of first lactation milk yield of 1500 Sahiwal daughters maintained at five farms. They utilized error variance, coefficient of determination, coefficient of variation and rank correlation methods for estimating the efficiency, accuracy and stability of different indices. The BLUP method was inferior in accuracy than least squares method as the coefficient of variation of data adjusted for non-genetic factors by BLUP method was higher as compared to coefficient of variation of data adjusted from least squares model. The rank correlation for both the methods of sire evaluation was high (0.9643) and statistically highly significant $(\mathrm{P}<$ 0.01).Different sire evaluation methods for Sahiwal and HF bulls were analyzed by Tajne and Rao (1990). The BLUP procedure was found most superior in appraisal of genetic merit of Sahiwal and Friesian sires for milk yield. Anacker and Diete (1990) reported that there were advantages of best linear unbiased prediction over the contemporary comparison method for the prediction of breeding value of dairy bulls. Based on the performance of the daughters of 1361 bulls, the estimated breeding value for milk yield, milk fat yield and milk protein yield were 10.9, 9.6 and 12.5 per cent more accurate using best linear unbiased prediction than contemporary comparison.

Singh et al., (1992) used least squares and best linear unbiased prediction (BLUP) method of sire evaluation on Hariana bulls for milk production and found that BLUP method of sire evaluation was most efficient than least squares method. The estimated prediction errors of BLUP were smaller than that from least squares method and correlations between BLUP predictions of part and complete lactation yields were higher than predictions from least squares method.

Raheja (1992) compared six methods of sire evaluation namely simple daughter average, herd mate comparison, contemporary comparison, ordinary least squares, regressed least squares and BLUP in Sahiwal cattle using 556 first lactation milk yield records and observed that the rank correlations and linear correlation coefficients among sires 
from different methods ranged from 0.46 to 0.86 and 0.48 to 0.94 , respectively. It was observed that BLUP method for estimation of breeding value of sires was most accurate in comparison to other methods.

Pundir and Raheja (1994) used multi trait BLUP procedure for estimating breeding values of Sahiwal sires for first lactation and lifetime performance traits. The rank and product moment correlation ranged between 0.22 to 0.91 and 0.21 to 0.84 , respectively, between first lactation and life time performance traits. They evaluated the Hariana and Sahiwal sires for first lactation and lifetime productivity. They applied multitrait best linear unbiased prediction (BLUP) procedure to estimate the breeding value of sires for different first lactation and life time traits. Multi trait mixed animal model included the year and season of calving as fixed effect and sire genetic group as random effect. They found that rank of sire for different traits were found almost similar for 4-5 per cent of top sires for first lactation and life time traits. Further, they suggested that sire should be selected on the basis of first lactation traits and selection or evaluation of dairy sires for lifetime could be used as additional criteria.

Gokhale and Mangurkar (1995) used five methods simple daughter average (SDA), herd mate comparison (HMC), CC, LS and LBUP for sire evaluation in Holstein crossbreds. They evaluated the sires on the basis of 305 day lactation milk yield. They reported that sire which ranked superiors by HMC, CC and BLUP methods, was ranked second by SDA and LS methods. Since rank correlation and simple product moment correlation under CC and BLUP method were highly correlated, they revealed that BLUP and/or CC methods can well be used for evaluation of sires under field conditions. Thus they concluded that the BLUP including the fixed effect of year and the random effect of sire are recommended.

Kuralkar et al., (1995) compared five models of BLUP for evaluating 323 progeny of 23 Sahiwal bulls on the basis of first lactation milk yield. The model one (BLUP) was more efficient than other models which includes fixed effects of herd (farm), season, year and sires as random effects. The rank correlation among models ranged from 0.64 to 1.00 . He evaluated sire using different non-genetic fixed effects in BLUP models for first lactation milk yield in Sahiwal. For this they used five best linear unbiased prediction (BLUP) models. Model I included fixed effects of herd (Farm), season, year and random effect of sires. Years were grouped into period in model II. The BLUP model I was found more efficient than the other models because standard errors of prediction in model were lower.

Deb et al., (1998) compared 56 sires of Brown Swiss and Jersey breeds by different sire evaluation methods namely daughter's average, contemporary comparison and least squares method used in Kerala under field conditions, using test-day milk yield of 2623 Brown Swiss $\mathrm{x}$ local and Jersey $\mathrm{x}$ local crossbred daughters. They reported that least squares method of sire evaluation was most superior to other methods used under field conditions in Kerala.

Jain (1996) used DFREML method under multiple trait models (two and three traits combination) for estimation of variance and covariance components and heritability. The variance components derived by these models were used for estimating breeding value of sires by BLUP method. He suggested that REML method should be used for estimation of genetic parameters and genetic evaluation of bulls. However, this would require information on pedigree and, therefore, 
maintenance of records. He also reported that when the target would be to improve more than one trait, all the traits should be included in model. However, the traits having very low heritability should not be taken in the model.

Espinosa et al., (2001) used data on 2618 records of milk production from 1991 to 1998 to estimate the breeding values in a Holstein dairy herd. The variance components were estimated by a REML with a derivative-free algorithm. It was concluded that the variance components of this study were reliable for prediction of breeding values of the animals. Smith (2002) described the procedure of restricted or residual maximum likelihood (REML) for linear models. He also described an explicit algorithm given for REML scoring which yielded the REML scoring together with their standard errors and likelihood values. The algorithm included a Leven bergMarquardt restricted step modification, which ensured the REML, increase at each iteration. Dhaka and Raheja (2000) estimated the breeding value of 26 Sahiwal sires using first lactation milk yield records of 380 daughters to compare the effectiveness of three different sire evaluation methods namely least squares, regressed least squares and BLUP. They concluded that BLUP method could be used in a situation where correct ratio of residual to sire variance is known and ordinary least squares could be used in a situation where the ratio of residual variance to sire variance is unknown. Gaur et al., (2001) estimated the breeding value of Frieswal sires using simple daughter's average, contemporary comparison (CC), least squares and BLUP procedures and computed rank correlations among the values obtained in order to judge the effectiveness of various methods. Rank correlations among breeding value of sires estimated from BLUP, LS and CC procedures were near to unity (0.96 to 0.97$)$. They suggested that either of the methods could be used for the evaluation of sires for breeding purpose.
Dhaka et al., (2002b) compared OLS, RLS and BLUP methods utilizing first lactation milk yield per day of lactation length in Hariana cattle and concluded that BLUP was the best method of sire evaluation when comparison was made on the basis of coefficient of kurtosis and it was the second best when rest of the two criteria (coefficient of skewness and standard error) were considered. Pundir et al., (2004) compared 33 Sahiwal sires using first lactation records of 514 daughters by different sire evaluation methods viz., simple daughter average, contemporary comparison, least squares and BLUP and suggested that BLUP and contemporary comparison procedures were almost equally good and superior over simple daughter average and least squares methods. Banik (2004) used LSM along with other methods (contemporary comparison, SRLS, BLUP and DFREML) for evaluation of Sahiwal sires and reported highly significant rank correlation of LSM with contemporary comparison (0.91), SRLS (0.98) and BLUP (0.85). These findings indicated that ranking of sires by these methods did not differ significantly. Dhaka et al., (2004) utilized first lactation milk yield per day of age at second calving records of Sahiwal cattle and inferred that OLS and RLS methods of sire evaluation have high and significant productmoment and rank correlations while these two methods have low and no-significant association with BLUP method. Mukherjee (2005) evaluated Frieswal sires using various methods. He observed that BLUP was comparatively more efficient than least squares method.

Banik and Gandhi (2006) estimated the breeding value of Sahiwal sires using least squares, BLUP and derivative free restricted maximum likelihood (DFRELM). The highest and lowest overall average breeding value of Sahiwal sires for first lactation 305d FLY was obtained by BLUP $(1520.72 \mathrm{~kg})$ and LS 
method (1502.22 kg), respectively. The accuracy, efficiency and stability of different sire indices were compared to judge their effectiveness. The error variance of univariate DFREML model was lowest and the coefficient of determination of fitting the model was highest $(33.39 \%)$ revealing that this method of sire evaluation was most efficient and accurate as compare to other methods. However, the BLUP method was most stable amongst all the methods having coefficient of variation (\%) very near to unadjusted data (18.72\% versus $19.89 \%)$.

The highest rank correlation (0.7979 to 0.9568) between different sire evaluation methods indicated that there was higher degree of similarity of ranking sires by different methods ranging from about 80 to 96\%. However, the DFREML method seemed to be the most effective sire evaluation as compared to other methods for the present set of data. Singh et al., (2006) estimated breeding value of Ongole bulls by BLUP procedure and ranked on the basis of their total lactation milk yield (TLMY).

Singh (2006) evaluated 38 Karan Fries bulls based on the part lactation records and complete 305-day milk yields of 340 Karan Fries cows and concluded that the least squares method was most efficient for estimating the breeding value of sires for first lactation 305-day or less milk yield followed by BLUP method.

Kumar (2007) estimated the breeding values of 114 Sahiwal sires for first lactation 305 days or less milk yield by applying various sire evaluation methods. Very high simple and rank correlation $(>0.9)$ between the breeding values of sires on the basis of first lactation 305-day or less milk yield from least squares with BLUP method suggested that both the methods were almost equally effective to discriminate amongst sires.
Mukherjee et al., (2007) evaluated 72 Frieswal sires for first lactation 305-day or less milk yield by using four methods viz. LSM, SRLS, BLUP and DFREML and reported that the most efficient DFREML method had highly significant $(\mathrm{P}<0.01)$ rank correlation with LSM (0.907), SRLS (0.909) and BLUP (0.956) methods. Raja (2010) evaluated 50 Sahiwal sires for first lactation 305-day or less milk yield by using four methods viz. LSM, SRLS, BLUP and DFREML and reported that the DFREML method was adjudged as the most efficient and accurate method of sire evaluation. Higher degree of rank correlations amongst the estimated breeding values of sires by different methods was observed.

Bajetha et al., (2015) the breeding value of sires estimated by three methods viz. Daughters average, Least squares and Simplified regressed least squares methods. The estimated breeding values (EVB's) showed large genetic variation between sires for first lactation traits. The association among the methods of sire evaluation ranging from 0.786 to 0.998 (product moment correlation) and 0.832 to 0.967 (rank correlation) for first lactation traits. Rank correlation among EBV's of sires indicates that all sires would not rank same for all first lactation traits. However, the ranks of sires for different traits revealed that 4-5\% top sires had similar rank for all first lactation traits. These results suggested that to improve productivity of herd major culling of bulls should be done on the basis of their daughter's first lactation milk yield.

Dongre and Gandhi (2014) estimated breeding values of 51 Sahiwal sires the actual and predicted FL305DMY by applying four sire evaluation methods viz., least squares, simple regressed least squares, best linear unbiased prediction and derivative free restricted maximum likelihood. The 
derivative free restricted maximum likelihood method had lowest error variance for both actual and predicted first lactation 305-days milk yields and it was considered to be the most efficient method. The BLUP method was second efficient followed by LSM and SRLS method.

Kamaldeep et al., (2015) conducted studies to compare progeny of 61 sires. Three sire evaluation procedures [ordinary least squares (OLS), regressed least squares (RLS), and best linear unbiased prediction (BLUP)] based on estimated breeding value of phase traits such as ascending phase milk yield (APY), peak phase milk yield (PPY),descending phase milk yield (DPY)and stayablity trait such as stayablity life (STAYAB) in Murrah buffalo. When comparison was made on the basis of coefficient of skewness, BLUP was found superior for APY, PPY, and DPY. When comparison was made on the basis of coefficient of kurtosis, OLS was better for APY and DPY whereas RLS was found superior for PPY and STAYAB. When coefficient of Determination, was considered OLS was found to be more accurate followed by RLS method for all the traits, whereas RLS method was most appropriate when coefficient of variation was considered.

Lodhi et al., (2015) estimated breeding values of sires using animal model (DFREML), best linear unbiased prediction (BLUP), least squares methods (LSM) and simple daughter average (D) sire evaluation. The average breeding value for age at first calving in crossbred bulls was found to be 1226.17 days by simple daughter's average method (D), 177.65 days by least squares method (LSM), 1998.42 days by best linear unbiased prediction and 1193.77 days by REML. The average breeding value for first lactation period in crossbred bulls was found to be 335.91days by simple daughter's average method (D), 323.7 days by least squares method (LSM), 324.01 days by using best linear unbiased prediction and 322.79 days by REML. The average breeding value for first dry period in crossbred bulls was found to be 131.19 days by simple daughter's average method (D),102.46 days by least squares method (LSM),106.34 days using best linear unbiased prediction and 101.56 days by REML. The average breeding value for first calving interval in crossbred bulls was found to be 464.02 days by simple daughter's average method (D), 426.24 days least squares method (LSM). 431.27 by best linear unbiased prediction and 424.73days by REML. The average breeding value for first service period was found to be 207.69 by simple daughter's average method (D), 173.93 days by least squares method (LSM), 166.36 days by best linear unbiased prediction and 170.53 days by REML.

The estimated breeding values of sire's for AFC estimated by LSM showed small genetic variation in compare to D, BLUP and REML method. While for FLP, FDP, FCI, and FSP estimated by BLUP showed small genetic variation in compare to D LSM and REML methods, therefore LSM and BLUP was considered as the most efficient methods out of all four methods of sire evaluation used in the present study.

Abbas et al., (2016) conducted studies on performance records of 927 Sahiwal Cattle daughters of 72 sires, to evaluate sire for first lactation and life time traits. The breeding value of sires was estimated by two methods viz. least squares and best linear unbiased prediction methods. BLUP method was found more efficient over the least squares method (LSM) based on estimated smaller value of coefficient of variation (C.V. \%) over that of least squares method. the BLUP using single trait viz. FSP, FDP, FCI, FLMY, PL and HL were having lowest error variances as compared to the least squares method (LSM). 
So, BLUP was the most efficient sire evaluation method.

Lodhi et al., (2016) evaluate sires for first lactation performance traits. The data were analyzed to estimate the breeding values of sires using Derivative Free Restricted Maximum Likelihood Method (DFREML), Best Linear Unbiased Prediction (BLUP), Least Squares Methods (LSM) and WOMBAT. The highest breeding value of sires for first lactation milk yield was obtained by LSM $(2779.19 \mathrm{~kg})$ and lowest by BLUP $(2629.80 \mathrm{~kg}$ ) than average breeding value respectively. The estimated breeding values estimated by BLUP showed small genetic variation in compare to WOMBAT, LSM and REML method. The error variance estimated by BLUP was found lowest than the other methods. Product moment correlation among breeding values of sires estimated by different methods ranged from 0.566 (LSM with BLUP) to 0.997 (WOMBAT with BLUP), whereas rank correlations of breeding value of sires ranged from 0.566 (LSM with BLUP) to 0.745 (WOMBAT with LSM). The higher rank correlations (0.566 to 0.745) between different sire evaluation methods revealed that there was higher degree of similarity of ranking sires by different methods ranging from about60 to 75 percent. The BLUP method was found to be more efficient, accurate and stable with lowest genetic variation amongst all four methods of sire evaluation used in the present study. Singh and Singh (2016)estimate breeding values and to compare various methods of sire evaluation viz. BLUP, LSM and sire evaluation methods on the basis of age at first calving, first service period, first lactation period, first dry period, and first calving interval. The accuracy, efficiency and stability of EBV's of sires for the first lactation and lifetime traits were compared by different methods to judge their effectiveness. The estimated breeding values of sires for all the first lactation traits by, LSM and BLUP revealed that EBV's of sires estimated by least squares method showed smaller genetic variation in comparison to and BLUP methods. The LSM was adjudged as the most efficient method of sire evaluation. The LSM had minimum error variance for most of the first lactation traits and considered to be more superior over other two methods i.e., and BLUP. The product moment correlations among the estimated breeding value of sires for first lactation traits by, LSM and BLUP methods ranged from medium to very high and significant $(\mathrm{P}<0.01)$ in all the three methods of sire evaluation. The rank correlations among the breeding value of sires estimated based on first lactation traits were medium to high and significant $(\mathrm{P}<0.01)$. The results indicated that least square method (LSM) had the lower error sum of square for all the first lactation traits and least square method (LSM) is relatively more accurate as compared to best linear unbiased prediction (BLUP) method but not overall. The LSM had higher R2 value for the first lactation traits as $40.50 \%$ (FLMY), $18.17 \%$ (FLL), $23.94 \%$ (FCI), $24.59 \%$ (FDP) and $48.47 \%$ (AFC) than the BLUP method. The estimated R2values are less which indicates that both methods are less suitable for present data. Therefore as for as stability is concerned among the methods of sire evaluation, the LSM method was most stable being its CV (\%) which is closest to the CV (\%) of unadjusted data. The rank correlations obtained were highest and statistically significant $(\mathrm{P}<0.01)$ and ranged from 0.74 (BLUP) to 0.88 (LSM). The highest rank correlations among the breeding values estimated from different methods revealed that rankings of sires were similar to the extent of 74 to 88 per cent from these methods of sire evaluation.

Dhawan et al., (2016) reported studies on sahiwal cattle using progeny records of 62 
sires for comparison of different sire evaluation method (SDA, OLS, RLS and BLUP) based on based on estimated breeding value of performance traits such as FLY, FPY, MLL, MCI and MSC When comparison was made on the basis of coefficient of skewness, OLS was found superior for estimation of breeding value for FLY, MLL and MSC whereas RLS for FPY and BLUP for MCI. When comparison was made on the basis of coefficient of kurtosis, SDA was better for FLY and FPY; OLS for MCI; and BLUP for MLL and MSC whereas RLS was found inferior. When standard error of the estimate was considered, RLS was found to be more accurate in case of FLY, MLL, MCI and MLL. It is recommended to use BLUP where correct ratio of residual variance to sire variances is known because it gives more reliable estimate of breeding value.

\section{References}

Abbas, S., Singh, C.V. and Barwal, R.S.(2016). Study of relative effectiveness of different sire evaluation methods in Sahiwal cattle. $J$. of Dairy, Veterinary and Animal Res., 3(6): 00104.

Anacker, G., Diete, G. (1990). Prediction of breeding value of progeny tested dairy bulls in the German Democratic Republic by means of BLUP method. Tierzucht.; 44(4):157-159

Bajeetha, G. (2006). Selection of sires by using different sire evaluation methods in crossbred cattle. Ph. D. Thesis, G.B. Pant Univ. of Agri. \& Technology, Pantnagar, Uttarakhand.

Banik, S. (2004). Sire evaluation in Sahiwal cattle. Ph.D. Thesis, NDRI, (Deemed University), Karnal, India.

Banik, S. and Gandhi, R.S. (2006). Animal model versus conventional methods of sire evaluation in Sahiwal cattle. Asian-Aust. J. Anim. Sci., 19(9):1225-1228.

Deb, S.M., Gurnani, M. and Chacko, C.T. (1998). Comparison of sire evaluation methods under field conditions. Indian J. Dairy Sci., 51(4): 210-215.
Dhaka, S.S. and Raheja, K.L. (2000). A comparison of sire evaluation methods. Indian J. Anim. Sci., 70(6): 643-644.

Dhaka, S.S., Chaudhary, S.R., Raheja, K.L. and Malik, B.S. (2002b). Accuracy of different methods of sire evaluation for production efficiency traits in Hariana cattle. Second international conference on sustainable agriculture for food, energy and industry. September 8-13, 2002. Beijing, China. p. 389-393.

Dhaka, S.S., Chaudhary, S.R., Raheja, K.L., Yadav, A.S. and Pander, B.L. (2004). Accuracy of different methods of sire evaluation for production efficiency traits in Sahiwal cattle. Indian J. Anim. Sci.,74: 296298.

Dhawan, S., Yadav, A.S., Dhaka, S.S. and Jakhar, V. (2016). Comparative efficiency of sire evaluation procedures in Sahiwal cattle. Haryana Vet. ;55(2):179-184.

Dongre, V.B. and Gandhi, R.S. (2014). Study of sire evaluation method in Sahiwal cattle. Ind. J. Vet. Anim. Sci. Res. ;43(3):174-179.

Espinosa, A.P., Rodríguez, A.F., Jiménez, C.J., Espinoza, V.J.L. and Núñez, D.R. (2001). Genetic evaluation of a Holstein dairy herd in Baja California Sur, utilizing an animal model with repeated measurements. Agrociencia.; 35(3):347-353. (Cited: Anim. Breed. Abstr, 70: 6873)

Gandhi, R.S. and Gurnani, M. 1991. Accuracy of different methods of sire evaluation in Sahiwal cattle. Indian Vet. J., 68(7):656662.

Gaur, G.K., Tripathi, V.N., Mukherjee, S. and Choudhary, V.K. 2001. Efficiency of sire evaluation procedures in Frieswal cattle. Indian J. Vet. Res., 10(2):1-6.

Gokhale, S.B. and Mangourkar, B.R. (1995). Field recording and sire evaluation under Indian condition. Indian J. Anim. Sci., 65(2): 203-207.

Jain, A., and Sadana, D.K. (1996). Sire evaluation using animal model and conventional methods in Murrah buffaloes. Asian Australasian J. Anim. Sci. 1996; 13(9):1196-1200.

Kamaldeep, Yadav, A.S., Dhaka, S.S., Mangotra, A. and Malik, A. (2015). Efficiency of sire evaluation methods by using phase and 
stayablity traits to improve milk yield of Murrah buffaloes. Indian J. Anim. Res. ISSN:0367-6722/ online ISSN: 0976-0555. DOI: 10.18805/ijar.5707.

Kumar, A. 2007. Genetic analysis of stayability in Sahiwal cattle. Ph.D. Thesis, NDRI, (Deemed University), Karnal, India. xi Bibliography

Kuralkar, S.V., Kothekar, M.D., Deshmukh, S.N., Gore, A.K. and Tajane, K.R. 1995. Sire evaluation using different non-genetic fixed effects in BLUP model for first lactation milk yield in Sahiwal. Indian J. Dairy Sci., 48(2):154-158.

Lodhi, G., Singh, C.V., Barbal, R.S., Shahi, B.N. and Dalal, D.S. (2015).Estimation of Breeding Values by Different Sire Evaluation Methods for Selection of Sires in CrossbredCattle. J Vet Sci Med Diagn.; 4:5.doi:10.4172/2325-9590.10001751.

Lodhi, Geeta, Singh, C.V., Barwal, R.S. and Shahi, B.N. (2016). Estimation of Sire Breeding Value by Animal Model and Conventional Methods for Milk Production in Crossbred Cattle. Journal of Agriculture and Crops.;2(3):31-34.

Lush, J.L. (1933). The bull index problem in light of modern genetics. J. Dairy Sci.; 16(6):501-522. 50.

Mukherjee, S. 2005. Genetic evaluation of Frieswal cattle, Ph.D. Thesis, NDRI, (Deemed University), Karnal, India.

Mukherjee, S., Joshi, B.K. and Gaur, G.K. 2007. Comparison of sire evaluation methods in Frieswal cattle. Indian J. Anim. Sci., 77(8): 773-776

Parekh, H.K.B. and Pande, A.B. 1982. Genetic evaluation of exotic sires under different environments and their accuracy. In: II world Cong. Genetics Applied to LivestockProd., Madrid, Spain, October 4-
8, 170-177.

Pundir, R.K. and Raheja, K.L. 1994. Relationship between sire's estimated breeding value for first lactation and lifetime traits in Sahiwal and Hariana cattle. Indian J. Anim. Sci., 64(11): 1219-1225.

Pundir, R.K., Malik, R.P.S. and Prakash, B. 2004. Comparison of different sire evaluation methods in Sahiwal cattle. Indian J. Anim. Sci., 74(2): 229-231.

Raheja, K.L. 1992. Comparison of progeny testing of Sahiwal sires by the different methods of sire evaluation. Indian J. Dairy Sci., 45(2): 64-69.

Raja, T.V. 2010. Part lactation records for Sahiwal sire evaluation. Ph.D. Thesis, NDRI, (Deemed University), Karnal, India.

Singh, J., Singh, C.V. (2016). Genetic and Phenotypic Parameters of First Lactation and Life Time Traits in Sahiwal Cows. $J$ Veterinar Sci. Technol.; 7:(4)1-3.i 76.

Singh, R. 1992. Genetic evaluation of Sahiwal bulls on the basis of daughter's multiple traits under selection. Ph.D. Thesis, NDRI, (Deemed University), Karnal, India.

Singh, S. 2006. Genetic evaluation of Karan Fries sires on the basis of part lactation milk yields. M.Sc. Thesis, NDRI, (Deemed University), Karnal, India.

Singh, S.K. 1992. Factors affecting some milk production efficiency traits in Sahiwal cattle. Indian J. Dairy Sci., 45(10): 522527.

Smith, K.S. (2002). An efficient algorithm for REML in Heteroscedastic Regression. $J$. Graphical Computational Stat.; 11:836-47.

Tajane, K.R. and Rai, A.V. 1990. Efficiency of sire evaluation methods to improve milk yield of Sahiwal x Holstein-Friesian cattle. Indian J. Anim. Sci., 60(2): 183-191.

\section{How to cite this article:}

Vikram Jakhar, A.S. Yadav and Dhaka, S.S. 2017. Comparative Studies on Different Sire Evaluation Methods: Review. Int.J.Curr.Microbiol.App.Sci. 6(11): 4256-4264. doi: https://doi.org/10.20546/ijcmas.2017.611.500 